Postgrad. med. J. (March 1967) 43, 173-183.

CASE REPORTS

\title{
Analgesic nephropathy
}

\author{
B. Hulme \\ B.Sc., M.B., Ch.B., M.R.C.P. \\ M.B., Ch.B. \\ Departments of Experimental Pathology and Pathology, \\ University of Birmingham
}

E. L. JONES

\section{Introduction}

There is evidence that renal failure can result from prolonged ingestion of analgesic tablets containing phenacetin (Annotation, Lancet, 1959; Leading articles, Brit. med. J., 1960, 1965). Cases from Switzerland, Denmark and Australia (Lindeneg et al., 1959; Jacobs \& Morris, 1962) and recently from Great Britain (Sanerkin \& Weaver, 1964) were all diagnosed post-mortem.

We report a case of chronic renal failure diagnosed as analgesic nephropathy 2 years before death from renal failure and malignant hypertension.

\section{Case report}

In December 1963, a 49-year-old married woman with one child gave a 6-month history of weakness, tiredness and pallor. On examination she was thin with severe mucosal pallor and no evidence of cyanosis or methaemoglobinaemia ; blood pressure, $145 / 95 \mathrm{mmHg}$; heart and optic fundi normal; normochromic normocytic anaemia (haemoglobin $5 \mathrm{~g} / 100 \mathrm{ml}$ ); blood urea, $270 \mathrm{mg} / 100 \mathrm{ml}$; serum creatinine, $9 \cdot 2 \mathrm{mg} / 100 \mathrm{ml}$; creatinine clearance, $4.5 \mathrm{ml} / \mathrm{min}$; $\mathrm{pH}, 7.21$; $\mathrm{PCO}_{2}, 29 \mathrm{mmHg}$; standard bicarbonate, $12 \cdot 2$ $\mathrm{mEq} / 1$.

$\mathrm{X}$-rays of the abdomen and bilateral retrograde pyelograms showed normal kidneys and calyces. Repeated bacteriological investigations of midstream specimens of urine were negative.

The moderate degree of uraemia, severe normochromic anaemia and gross disturbance of acid base balance associated with normal size kidneys and no evidence of pyelonephritis suggested 'analgesic nephropathy'. The patient admitted to taking twelve to twenty APC (BPC) tablets daily for severe pain in both arms and neck following a fracture dislocation of the sixth cervical vertebra in 1956, when she was in hospital for 14 weeks, no evidence of renal disease then being found. It was estimated that over $3 \mathrm{~g}$ of both phenacetin and aspirin had been taken daily for at least 8 years.
Treatment consisted of: blood transfusion; high calorie/low sodium/low potassium/low protein diet; oral sodium bicarbonate supplements; and an increased fluid intake. Two weeks later, whilst still normotensive she suddenly had a grand mal epileptic fit, was unconscious for $24 \mathrm{hr}$ and nearly blind for 1 week. It was assumed that this deterioration was due to water intoxication and following fluid restriction to $500 \mathrm{ml}$ daily she lost $7 \mathrm{~kg}$ in weight. In February 1964 the urine output could not be increased above 1.5-2 litres daily.

Six weeks later she complained of blurring of vision and showed severe hypertensive retinopathy with haemorrhages and papilloedema. The blood pressure was then $225 / 110 \mathrm{mmHg}$ and the blood urea $160 \mathrm{mg} / 100 \mathrm{ml}$. The blood pressure fell on treatment with bethanidine sulphate. There was still no evidence of urinary tract infection. By September 1965 the blood pressure became difficult to control and the urinary output decreased and averaged only $500-700 \mathrm{ml}$ daily, with a glomerular filtration rate of $0.8 \mathrm{ml} / \mathrm{min}$ as measured by means of radioactive vitamin $B_{12}$ (Nelp, Wagner \& Reba, 1964). The blood urea was maintained below $250 \mathrm{mg} / 100 \mathrm{ml}$ on a very low protein diet until 4 days before death when she developed severe epistaxis, drowsiness and anuria and passed into a terminal uraemic coma in November 1965.

\section{Necropsy}

The body (height, $5 \mathrm{ft} 4$ in.; weight, $36.55 \mathrm{~kg}$ ) showed pallor of the skin, oedema of both legs and a blotchy ecchymotic rash over the trunk and forearms.

Kidneys (125 g) were symmetrically contracted and pale. On both sides: cortex was considerably reduced in thickness and only $2-3 \mathrm{~mm}$ wide (normal $1 \mathrm{~cm}$ ); corticomedullary junction indistinct ; medulla congested and tips of papillae ragged and dark brown in colour (Fig. 1), due to bilateral necrosis; interlobar vessels prominent, thick walled and 'gritty', several larger arteries markedly atheromatous; capsules stripped easily; outer 


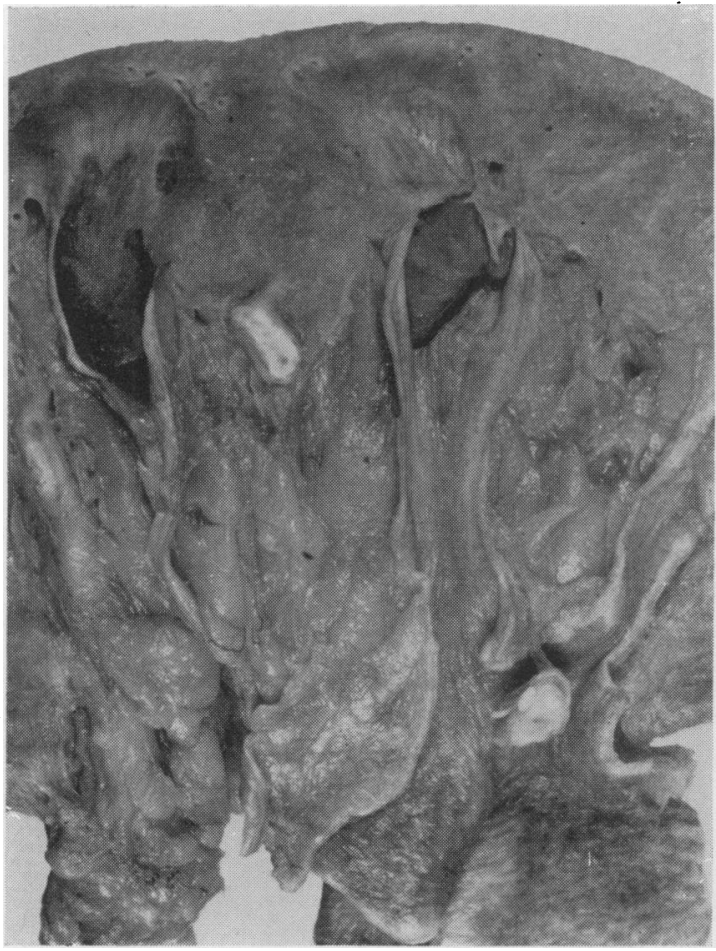

Fig. 1. Kidney showing ragged dark brown papillae. Cortex shrunken. Severe atheroma.

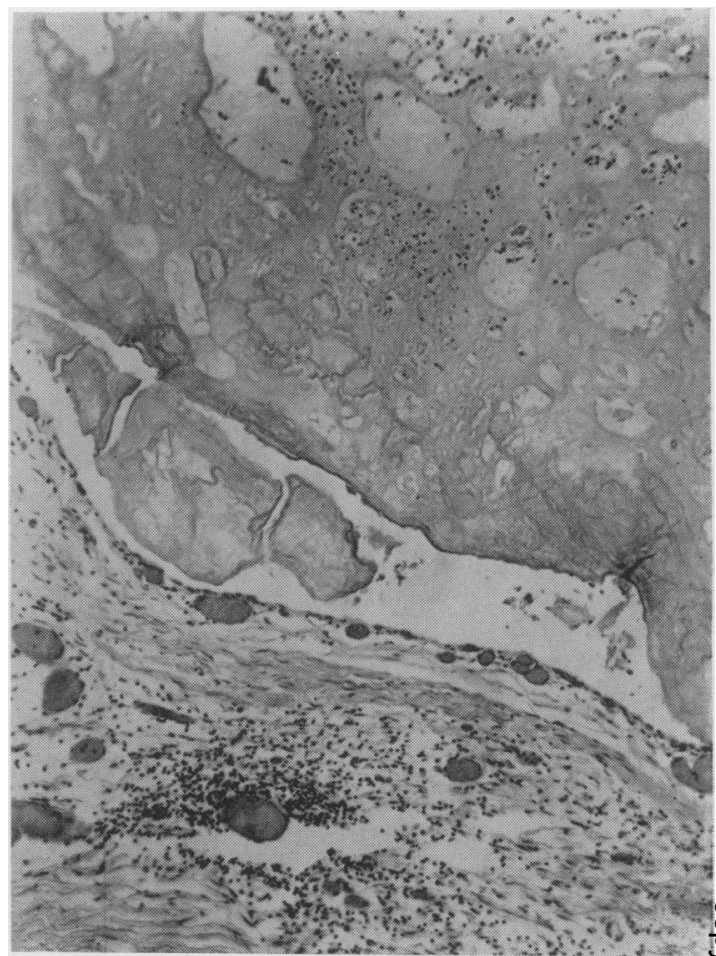

FIG. 2. Pale ghost outlines of necrotic tubules. The papilla has become detached from viable tissue (lower left). H \& E, $\times 100$. surfaces smooth and even; no evidence of infection ; pelvic fat slightly increased; calyceal and pelvic mucosae pebbly, uneven and very congested. Ureters normal and not obstructed. Renal veins and the right renal artery normal. Left artery divided into two branches and the distal segment was narrowed by atheroma over $1-2 \mathrm{~cm}$. Heart (weight, $505 \mathrm{~g}$ ): marked left ventricular hypertrophy, average thickness $20 \mathrm{~mm}$ (normal $15 \mathrm{~mm}$ ). Right ventricle showed slight hypertrophy. Well-marked fibrinous pericarditis. Coronary arteries showed widespread calcified atheroma with patchy stenosis. Minimal patchy myocardial fibrosis. Lungs: extensive bilateral oedema and basal congestion. Bilateral pleural effusions of clear yellow fluid $(600$ and $800 \mathrm{ml})$.

\section{Histology}

Kidneys showed marked papillary necrosis, only the ghost outlines of the tubules and ducts of Bellini remaining, associated with pronounced granular calcification and minimal infiltration with neutrophil polymorphs. One papilla is detached (Fig. 2).

Most of the glomeruli show total hyaline fibrosis. A few surviving glomeruli show only periglomerular fibrosis. Bowman's spaces are sometimes dilated and the capillary loops compressed and bloodless. There is a marked increase of interstitial fibrous tissue in the cortex and a heavy cellular infiltrate, mainly lymphocytic (Fig. 3). There is also severe interstitial fibrosis, shrinkage and atrophy of tubules and a marked chronic inflammatory exudate throughout the medulla. In places tubular dilatation is probably secondary to the papillary necrosis (Dawborn et al., 1966). Several interlobar arteries show extensive atheroma and calcification. The arterioles show severe intimal fibroelastosis, reduplication of the internal elastic lamina and medial hypertrophy. Iliac crest bone biopsy: undecalcified sections stained by the von Kossa method show normally calcified trabeculae of lamellar bone. A few osteoid seams of normal width are present. No evidence of osteomalacia or osteoporosis. Decalcified sections show evidence of secondary hyperparathyroidism, with fibrosis of the marrow spaces and osteoclastic resorption of the trabeculae.

There were no other relevant histological abnormalities. 


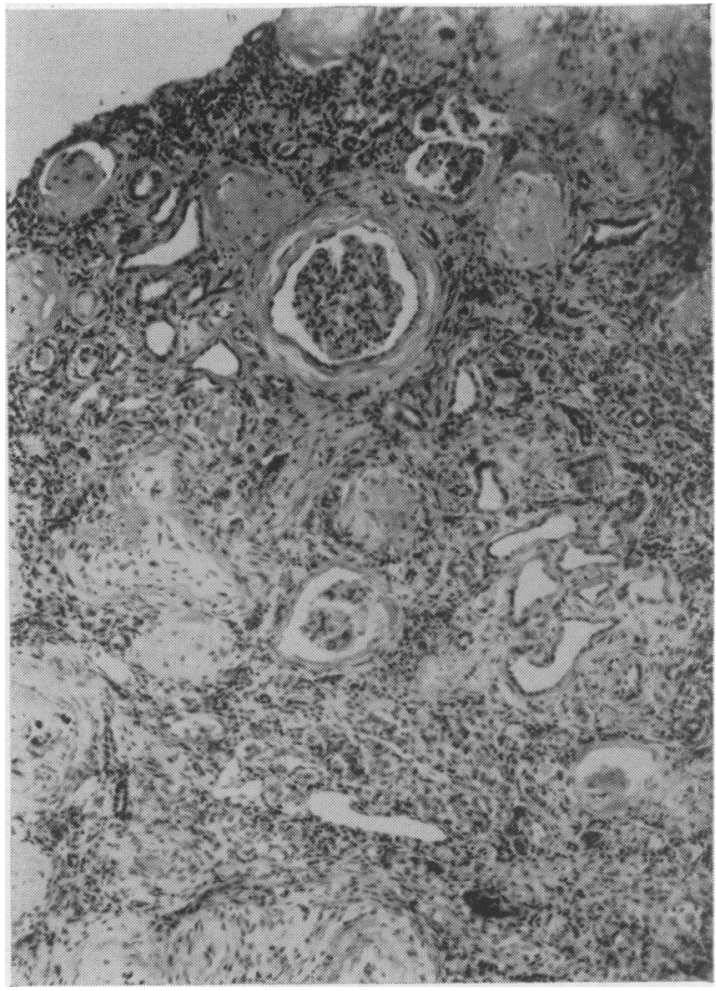

FIG. 3. Marked interstitial fibrosis of cortex, heavy chronic inflammatory cell infiltration and severe tubular atrophy and dilatation. Ehrlichs haematoxylin and Van Gieson, $\times 100$.

\section{Discussion}

There is now good evidence that prolonged ingestion of analgesics can cause chronic bilateral renal papillary necrosis and consequent renal failure. The possibility must always be considered when this condition is found in the absence of diabetes mellitus and hydronephrosis.

In some cases it may be difficult to prove the causative role of ingestion of analgesics, though in this case the evidence is convincing. First, there was no evidence of infection or obstruction of the urinary tract; second, diabetes mellitus was not present ; third, prior to the ingestion of analgesics the patient had no signs of renal or cardiovascular disease; and fourth, the patient admitted taking between twelve and twenty analgesic tablets per day, a cumulative dose of at least $13 \mathrm{~kg}$ of phenacetin and $13 \mathrm{~kg}$ of acetylsalicylic acid.

The current evidence suggests that phenacetin in excess of $1 \mathrm{~g} /$ day for at least 1 year must be consumed before the kidney is affected. Despite cessation of all analgesics the renal disease progressed and at necropsy small symmetrically contracted kidneys were found, though 2 years previously radiography indicated they were of normal size.

Spühler \& Zollinger (1953) first suggested that prolonged ingestion of analgesics resulted in chronic papillary necrosis, and considered an increase in the number of cases found to be due to an alteration in the manufacture of phenacetin in the early 1940s. The toxic chemical is believed to be the impurity acetic-4-chloranilide; reports have been predominantly from Denmark, Switzerland and Australia where the phenacetin consumption per head of population is believed to be higher than in Britain (Boyd, 1964).

The great majority of cases are middle-aged women with a history of migraine and, more recently, histories of previous gastric ulceration have been reported (Olafsson, Gudmundsson \& Brekkan, 1966; Dawborn et al., 1966). At least $50 \%$ of patients have associated pyelonephritis. There is usually severe renal failure, a refractory normochromic normocytic anaemia and severe acid base changes; death usually occurs within a few months of diagnosis and at necropsy the typical renal changes are found.

In some patients who discontinued analgesics, follow-up studies for at least 1 year have not shown improvement in renal function (Reynolds \& Edmondson, 1963).

Though the evidence linking analgesic abuse and renal failure is circumstantial, all tablets containing phenacetin have been banned in Switzerland since 1961 ; in the U.S.A. all bottles containing phenacetin tablets must carry a warning stating that if consumed in excess there is a risk of severe renal damage (Leading article, J. Amer. med. Ass., 1964); and the Pharmaceutical Society of Great Britain issued a warning in March 1965 on the association between phenacetin and renal damage (Leading article, Brit. med. J., 1965). If phenacetin or tablets containing phenacetin are capable of producing renal damage, the problem is considerable: the Monthly Index of Medical Specialities (1965) lists thirty-three ethical preparations containing phenacetin and there are at least thirty-six proprietary preparations containing phenacetin available without prescription. As there are now a number of drugs with analgesic and antipyretic properties comparable to phenacetin there seems little justification for its continued administration.

\section{Summary}

A case of analgesic nephropathy in a previously healthy middle-aged female is described. The diagnosis was made 2 years before her death, and despite cessation of all analgesic tablets progressive renal failure terminated in uraemia and malignant hypertension. At necropsy there was 
chronic bilateral renal papillary necrosis. Attention is drawn to the dangers of prolonged analgesic abuse.

\section{Acknowledgments}

We would like to thank Dr E. Bulmer for permission to record this case. We are also grateful to Dr D. B. Brewer for his advice and criticism, Mr S. A. Gaunt for the photography and Mrs J. Seabourne for secretarial assistance.

\section{References}

AnNotation (1959) Phenacetin nephropathy. Lancet, i, 84.

BOYD, D.H.A. (1964) The use and abuse of phenacetin. Scot. med. J. 9, 423.

Dawborn, J.K., Fairley, K.E., Kincaid-Smith, P. \& KING, W.K. (1966) The association of peptic ulceration, chronic renal disease and analgesic abuse. Quart. J. Med. 137, 69.

EDITORIAL (1964) Analgesic abuse and the kidneya commentary. J. Amer. med. Ass. 190, 238.
JACOBS, L.A. \& MORRIS, J.G. (1962) Renal papillary necrosis and the abuse of phenacetin. Med. J. Aust. 11, 531.

LEADING ARTIClE (1960) Renal risks of phenacetin. Brit. med. J. i, 714.

LeADING ARTICLE (1965) Phenacetin and the kidney. Brit. med. J. i, 673.

Lindeneg, O., Fischer, S., Pedersen, J. \& Nissen, N.I. (1959) Necrosis of the renal papillae and prolonged abuse of phenacetin. Acta med. scand. 165, 321.

Monthly Index of Medical Specialities (1965) Vol. 7, No. 11.

NelP, W.B., WAGNER, H.N. \& REBA, R.C. (1964) Renal excretion of vitamin $B_{12}$ and its use in measurement of glomerular filtration rate in man. J. Lab. clin. Med. 63, 480.

Olafsson, O., Gudmundsson, W.R. \& Brekkan, A. (1966) Migraine, gastritis and renal papillary necrosis. Acta med. scand. 179, 121.

REYNOLDS, T.B. \& EDMONDSON, H.A. (1963) Chronic renal disease and heavy use of analgesics. J. Amer. med. Ass. 184, 435.

SANERKIN, N.G. \& WeAver, C.M. (1964) Chronic phenacetin nephropathy ('chronic interstitial nephritis') with papillary necrosis. Brit. med J. i, 288.

SPUHLER, O. \& ZOLlinger, H. (1953) Die chronish interstitielle Nephritis. Z. klin. Med. 151, 1.

\title{
Mast cell disease
}

\author{
T. I. MCBRIDE \\ M.B., M.R.C.P. \\ Registrar in Medicine
}

G. A. McDonALD
M.D., M.C.Path.
Consultant Haematologist

\author{
W. P. Duguid \\ M.B., M.C.Path. \\ Consultant Pathologist
}

The Royal Infirmary, Glasgow

\section{Introduction}

In recent years much interest has been focused on the physiology and pathology of the mast cell. It is accepted that the mast cell features in a wide variety of disorders and mastocytosis has been proposed as a generic name for syndromes in which extensive mast cell involvement is present. Selye (1965) has collected and analysed the relevant literature on mast cells and this has been used as the main reference text in the preparation of this report. The patient described is of particular interest in that he had a syndrome which was first considered to be a non-specific mastocytosis, but in which several unusual features were discovered.

\section{Case report}

A 63-year-old male clerk was first seen at the Medical Out-Patient Department of Glasgow Royal Infirmary where he was discovered to be anaemic and to have hepatosplenomegaly. He was consequently admitted for further investigation. The presenting complaints were dyspnoea, some chest tightness and nausea of only 6 weeks' duration. Detailed questioning revealed no other features of note in the past history-in particular there was no history of drug ingestion, episodic flushing or of any haemorrhagic tendency.

Physical examination revealed a well-developed man with no evidence of recent weight loss. The mucous membranes were pale and the liver and spleen were each palpable 2 finger breadths below the respective costal margins. Examination of the other systems revealed no abnormality. In particular no skin lesions were present.

\section{Investigations}

$\mathrm{Hb}, 6.6 \mathrm{~g} / 100 \mathrm{ml}$; PCV, $22 \%$; WBC, $2100 / \mathrm{mm}^{3}$ -with a normal distribution in the differential count. Platelet count, $98,000 / \mathrm{mm}^{3}$; ESR, $35 \mathrm{~mm}$ in the 1st hour (Westergren). The blood film showed anisocytosis and poikilocytosis. The liver 